\title{
Multivariate analysis and character association studies for yield and nutritional characters in swarna and type 3 RIL population of rice (Oryza sativa $\mathrm{L}_{\text {.) }}$
}

\author{
Darmagaru Shivani ${ }^{1,2^{*}}$, Cheruvuri Naga Neeraja ${ }^{1}$, Chandragiri Cheralu ${ }^{2}$ and Vuppu Gouri Shankar ${ }^{2}$ \\ ${ }^{1}$ ICAR-Indian Institute of Rice Research, Rajendranagar, Hyderabad, India \\ ${ }^{2}$ Professor Jayashankar Telangana State Agricultural University, Rajendranagar, Hyderabad, India
}

\section{Article history:}

Received: 4 Apr., 2021

Revised: 25 May, 2021

Accepted: 13 July, 2021

\section{Citation:}

Shivani D, CN Neeraja, C Cheralu and VG Shankar. 2021. Multivariate Analysis and Character Association Studies for Yield and Nutritional Characters in Swarna and Type 3 RIL Population of Rice (Oryza sativa L.). Journal of Cereal Research 13(2): 180-187. http:// doi.org/10.25174/2582-2675/2021/113440

\section{"Corresponding author:}

E-mail: shivani.42agrico@gmail.com

(C) Society for Advancement of Wheat and Barley Research

\begin{abstract}
The investigation was carried out in one hundred Swarna X Type 3 RIL population of rice to understand the association among yield, yield attributing and nutritional traits. Their direct and indirect effects on the grain yield using correlation and path analysis and the principal component analysis was assessed using multivariate analysis. Significant differences were observed among the RIL population for the traits studied. High values of heritability and genetic advance were observed for plant height, panicle weight, number of filled grains per panicle, panicle weight, 1000-seed weight, grain yield per plant, grain iron and zinc concentration. Character association for the yield attributing traits at both genotypic and phenotypic level revealed significant positive association of grain yield per plant with test weight and plant height. Path coefficient analysis revealed that test weight had highest direct positive effect on grain yield per plant followed by plant height and filled grains per panicle. PCA showed that a cumulative variance of $32.5 \%$ from PC1 attributed by grain iron, grain zinc, plant height and test weight would be beneficial in contributing to the total morphological diversity. RILs P45 and P57 have shown higher grain yield per plant with high iron and zinc concentrations. Thus, the trait test weight that showed positive and direct association with grain yield can be focused in selection and can be utilized for improvement in future breeding programmes.
\end{abstract}

Key words: Correlation, Path, PCA analysis, Variability, Yield and Nutritional traits

\section{Introduction}

Rice (Oryza sativa L.) is the staple food crop for more than half of the world's population. More than $90 \%$ of the world's rice is grown and consumed in Asia, whereas $50 \%$ of the population depends on rice for food (Tenorio et al. 2013). In India, rice accounts for more than $43 \%$ of food grain production. It has been estimated that there is a need for $60 \%$ more rice production for the expected 9.7 billion global human population by 2050 (Wani et al. 2020). Micronutrient deficiency such as $\mathrm{Zn}$ and Fe is rampant among Indian population particularly, in the children and pregnant woman (Ritchie et al. 2018), therefore, identification of suitable material rich in $\mathrm{Zn}$ and Fe content along with yield needs utmost attention for enhancing productivity and production of rice.

The knowledge on genetic variability study is of great significance for the success of any plant breeding 
programme. Heritability and genetic advance are the most important selection parameters as heritability estimates along with genetic advance helps in envisaging the gain under selection. Heritability along with genetic advance will help in predicting the ultimate effect for selecting superior varieties (Ali et al. 2002). Correlation and path analysis determines the association between yield and its components and also brings out the relative importance of their direct and indirect effects with grain yield. Essentially, this kind of analysis could benefit the breeder to choose appropriate selection strategies to improve grain yield.

Multivariate analytical tools have found widespread use in describing the inherent variation among crop genotypes. These tools includes cluster and principal component analysis. Principal component analysis has been helpful in identifying the contribution and the importance of each component to the total variance (Noirot et al. 1996) and it has been successfully used in the evaluation of crop germplasm for understanding the correlation and relationship among the variables studied (Zafar et al. 2008). Based on these points, the present investigation was carried out with the objective to quantify the genetic variability present in the Swarna x Type 3 RIL population which may be exploited in genetic improvement of rice for grain zinc and iron in addition to yield.

\section{Materials and Methods}

The material for the present study consisted of one hundred RIL population developed from the cross Swarna x Type 3 using Single Seed Decent method. Field experiment was conducted at ICAR-Indian Institute of Rice Research, Hyderabad. The experiment was laid out in Augmented Block Design including four checks (Swarna, Type 3, BPT 5204 and Chittimuthyalu). Checks were replicated in each block. All the cultural practices are followed as per the package of practices adopted for rice.

Observations were recorded on five randomly selected plants for days to 50 per cent flowering, plant height, panicle length number of productive tillers per plant, panicle weight, number of filled grains per panicle, test weight, and grain yield per plant. Grain iron and zinc concentration were determined by X-Ray fluorescence Spectrometry (XRF) (EDXRF, model-X-supreme 8000) (Paltridge et al., 2012)

Data for the above traits were subjected to statistical analysis viz., Analysis of variance (ANOVA), genetic variability components such as phenotypic coefficient of variation (PCV) and genotypic coefficient of variation $(\mathrm{GCV})$, heritability and genetic advance. Correlation coefficients, principal component analysis (PCA) and principal component score was derived using the software SAS v.9.3 to reveal the best relationships among traits.

\section{Results and Discussion}

In any crop genetic variability is pre-requisite for selection of superior genotypes over the existing cultivars. Variance analysis for all the characters revealed significant differences among the genotypes studied. For all the characters under the study, phenotypic coefficient of variation $(\mathrm{PCV})$ in general was higher than genotypic coefficient of variation $(\mathrm{GCV})$ indicating the influence of environment on the expression of these characters (Table 1). However, the difference between PCV and GCV was less for the characters viz, plant height, panicle weight, number of filled grains per panicle and single plant yield indicating low environmental influence and predominance of genetic factors controlling variability of these traits. Similar results were reported by Lakshmi et al. (2017) for plant height, by Nandeshwar et al. (2015) for panicle weight and by Sameera et al. (2015) for single plant yield. The information of genetic variability alone is of limited use to the breeder unless it is supplemented with the evidence on heritability, which gives a measure of the heritable portion of the total variation. Genetic advance is reliant on phenotypic variability and heritability in addition to selection intensity, so the heritability estimates in addition with genetic advance will be more effective and reliable in predicting the response to selection (Johnson et al. 1955). Heritability in the broad sense includes both additive and non-additive gene effects (Hanson et al. 1956). Whereas, narrow sense heritability includes only additive components (Johnson et al. 1955). 
Table 1. Estimates of range, mean and genetic parameters for yield and nutritional traits in rice

\begin{tabular}{|c|c|c|c|c|c|c|c|}
\hline \multirow{2}{*}{ Characters } & \multirow[t]{2}{*}{ Mean } & \multicolumn{2}{|c|}{ Range } & \multicolumn{2}{|c|}{ Coefficient of variability } & \multirow{2}{*}{$\begin{array}{l}\text { Heritability } \\
\text { (\%) broad } \\
\text { sense }\end{array}$} & \multirow{2}{*}{$\begin{array}{c}\text { Gen.Adv as } \\
\text { per cent of } \\
\text { Mean } \\
\text { (at 5\%) }\end{array}$} \\
\hline & & Min. & Max. & PCV \%) & GCV (\%) & & \\
\hline Days to $50 \%$ Flowering & 114 & 101.0 & 125.0 & 3.36 & 2.93 & 76.03 & 5.26 \\
\hline Plant Height $(\mathrm{cm})$ & 134.6 & 77.0 & 167.0 & 12.64 & 12.57 & 98.74 & 25.72 \\
\hline Panicle Length $(\mathrm{cm})$ & 23.9 & 16.8 & 28.2 & 7.67 & 7.11 & 85.84 & 13.56 \\
\hline No. of productive tillers/ plant & 10.3 & 8.2 & 13.4 & 10.39 & 9.17 & 77.93 & 16.67 \\
\hline Panicle weight $(\mathrm{g})$ & 4.0 & 2.2 & 6.0 & 22.19 & 22.10 & 99.23 & 45.35 \\
\hline Number of filled grains/ panicle & 105.4 & 32.3 & 171.0 & 33.58 & 33.21 & 97.79 & 67.65 \\
\hline 1000 grain weight $(\mathrm{g})$ & 18.8 & 9.0 & 24.5 & 15.51 & 14.30 & 90.14 & 27.95 \\
\hline Grain Iron conc (ppm) & 9.7 & 5.2 & 16.1 & 16.44 & 14.00 & 72.56 & 24.57 \\
\hline Grain Zinc conc (ppm) & 21.3 & 14 & 28.5 & 13.47 & 13.02 & 93.47 & 25.93 \\
\hline Grain yield/ plant (g) & 21.7 & 11.7 & 33.2 & 20.54 & 20.22 & 96.98 & 41.03 \\
\hline
\end{tabular}

In the present study, heritability in broad sense was estimated. High broad sense heritability was recorded for all the characters under study. High heritability coupled with genetic advance was found to be highest for plant height (98.74 and 25.72\%), panicle weight (99.23 and $45.35 \%)$, number of filled grains per panicle (97.79 and $67.65 \%), 1000$ seed weight (90.14 and 27.95\%), grain zinc (93.47 and 25.93\%), iron (72.56 and 24.57\%) and single plant yield (96.98 and 41.03\%). The study clearly showed that there is ample scope to improve all these characters through selection. These results are in conformity with Devi et al. (2016), Lakshmi et al. (2017) for plant height, number of filled grains per panicle and 1000 seed weight, Satish et al. (2017) for panicle weight, Karande et al. (2015), Lakshmi et al. (2017) for single plant yield. Gangashetty et al. (2013) reported similar results for grain zinc and iron concentration.

The complex character such as grain yield is based on the total net effect produced by various yield components relating with one another. The present investigation revealed that there is adequate genetic variability present in the material studied. Among all the characters, plant height, number of filled grains per panicle, panicle weight, 1000-seed weight, grain yield per plant, grain iron and zinc concentration recorded high heritability as well as high genetic advance, indicating the presence of considerable variation and additive gene effects. Hence, response to selection would be quite possible.

\subsection{Correlation between characters}

Selection based on the magnitude and direction of association between yield and yield attributes is very important in identifying the key characters, as this information can be exploited for crop improvement by designing suitable breeding programmes. Phenotypic and genotypic correlations between yield, yield attributes and nutritional components viz, days to 50 per cent flowering, plant height, panicle length, number of tillers per plant, panicle weight, number of filled grains per panicle, test weight, single plant yield, grain zinc and grain iron content were computed separately for the RIL population considering in this study. The results are presented under Table 2. Grain yield per plant was significantly positively correlated with plant height $(0.21500)$ and test weight (0.39373). Test weight showed significant and positive correlation with panicle weight. Similar findings were reported by Nandeshwar et al. (2015) and Satish et al. (2017). Significant positive association is also observed for grain iron with grain zinc content. Other yield components viz, Days to $50 \%$ flowering, panicle length, number of tillers per plant, panicle weight and filled grains per panicle showed non-significant positive association with grain yield. Similar findings were earlier reported by Rahman et al. (2014) Seyoum et al. (2012) and Rao et al. (2014) for panicle length, number of tillers per plant and number of filled grains per panicle. While a negative association was found with grain iron and grain zinc content. Similar results were reported by Nagesh $e t$ al. (2013) for grain zinc and iron content. 
Table 2. Genotypic and phenotypic correlation coefficients for yield and nutritional traits in rice

\begin{tabular}{|c|c|c|c|c|c|c|c|c|c|c|}
\hline & DFF & PH & PL & NT & PW & FGP & TW & $\mathrm{Fe}$ & $\mathrm{Zn}$ & SPY \\
\hline DFF & 1.0000 & $-0.25237^{* *}$ & -0.01350 & -0.06742 & 0.12325 & 0.06909 & 0.14333 & -0.05973 & -0.13330 & 0.08072 \\
\hline $\mathrm{PH}$ & & 1.0000 & 0.11451 & 0.09012 & 0.10340 & -0.02478 & 0.02336 & $-0.22693^{*}$ & $-0.18858^{*}$ & $0.21500^{*}$ \\
\hline PL & & & 1.0000 & -0.00590 & -0.08740 & 0.01530 & -0.03999 & -0.00078 & -0.11041 & 0.03064 \\
\hline NT & & & & 1.0000 & -0.02825 & -0.05510 & -0.04068 & -0.05784 & -0.07053 & 0.03782 \\
\hline PW & & & & & 1.0000 & -0.02298 & $0.28880^{* *}$ & -0.09093 & -0.01831 & 0.10992 \\
\hline FGP & & & & & & 1.0000 & 0.02035 & $-0.19668^{*}$ & -0.08036 & 0.10278 \\
\hline TW & & & & & & & 1.0000 & -0.12862 & -0.04148 & $0.39373^{* *}$ \\
\hline $\mathrm{Fe}$ & & & & & & & & 1.0000 & $0.66919^{* *}$ & $-0.40593^{* *}$ \\
\hline $\mathrm{Zn}$ & & & & & & & & & 1.0000 & $-0.42433^{* *}$ \\
\hline SPY & & & & & & & & & & 1.0000 \\
\hline
\end{tabular}

* and ** Indicate significance at 5\% and 1\% levels respectively; DFF: Days to 50\% flowering; PH: Plant height; PL: Panicle Length; NT: Total number of tillers per plant; PW: Panicle weight; FGP: Number of filled grains per panicle; TW: Test weight; Fe: Grain iron; Zn: Grain zinc; SPY: Single plant yield.

\subsection{Path coefficient analysis}

Correlation alone does not provide the true contribution of the characters towards the yield, the genotypic correlations were partitioned into direct and indirect effects through path coefficient analysis, which allows separating the direct effect and indirect effects through additional attributes by apportioning the correlations (Wright, 1923) for better interpretation of cause and effect relationship. The estimates of path coefficient analysis for yield, yield related and nutritional traits given in Table 3. Among the characters studied at genotypic level, Test weight $(0.3679)$ had highest direct positive effect on grain yield per plant followed by plant height (0.1298), number of filled grains per panicle (0.0502), number of tillers per plant $(0.016)$ and days to fifty percent flowering $(0.0147)$. On the other hand, direct negative effect to grain yield was recorded by panicle length, panicle weight, grain iron and grain zinc content.

Table 3. Path analysis of direct and indirect effects for yield and nutritional traits in rice

\begin{tabular}{lccccccccc}
\hline & DFF & PH & PL & NT & PW & FGP & TW & Fe & Zn \\
\hline DFF & $\mathbf{0 . 0 1 4 7}$ & -0.0037 & -0.0002 & -0.0010 & 0.0018 & 0.0010 & 0.0021 & -0.0009 & -0.0020 \\
PH & -0.0327 & $\mathbf{0 . 1 2 9 8}$ & 0.0149 & 0.0117 & 0.0134 & -0.0032 & 0.0030 & -0.0294 & -0.0245 \\
PL & 0.0001 & -0.0006 & $-\mathbf{0 . 0 0 5 3}$ & 0.0000 & 0.0005 & -0.0001 & 0.0002 & 0.0000 & 0.0006 \\
NT & -0.0011 & 0.0014 & -0.0001 & $\mathbf{0 . 0 1 6 1}$ & -0.0005 & -0.0009 & -0.0007 & -0.0009 & -0.0011 \\
PW & -0.0033 & -0.0028 & 0.0023 & 0.0008 & $-\mathbf{0 . 0 2 6 8}$ & 0.0006 & -0.0077 & 0.0024 & 0.0005 \\
FGP & 0.0035 & -0.0012 & 0.0008 & -0.0028 & -0.0012 & $\mathbf{0 . 0 5 0 2}$ & 0.0010 & -0.0099 & -0.0040 \\
TW & 0.0527 & 0.0086 & -0.0147 & -0.0150 & 0.1063 & 0.0075 & $\mathbf{0 . 3 6 7 9}$ & -0.0473 & -0.0153 \\
Fe & 0.0072 & 0.0274 & 0.0001 & 0.0070 & 0.0110 & 0.0237 & 0.0155 & $-\mathbf{0 . 1 2 0 6}$ & -0.0807 \\
Zn & 0.0397 & 0.0562 & 0.0329 & 0.0210 & 0.0055 & 0.0239 & 0.0124 & -0.1993 & $-\mathbf{0 . 2 9 7 8}$ \\
SPY & 0.0807 & 0.2150 & 0.0306 & 0.0378 & 0.1099 & 0.1028 & 0.3937 & -0.4059 & -0.4243 \\
\hline
\end{tabular}

Thus, it is understood that test weight can be considered as the major yield contributing character. These results are in accordance with the previous studies conductedby Kalyan et al. (2017), Lakshmi et al. 2017 and Priya et al.
2017. It is also understood that the increased grain yield through the direct effect of test weight is the indirect effect of number of tillers per plant and panicle weight followed by moderate to low indirect effects of panicle 
length and number of filled grains per panicle. These findings are in concurrence with earlier reports (Padmaja et al. 2011, Kalyan et al. 2017). Thus, test weight appears to be important trait on which emphasis can be laid as a selection criterion for yield.

\subsection{Principal component analysis}

The PCA was performed for all the ten traits among the RIL population of rice as indicated in Table 4. On the basis of scree plot (Figure 1), five principal components having Eigen values more than 1 were chosen which showed about $66.6 \%$ variability among the studied traits. The PC1 had 17.9\%, PC2 showed 14.6\%, PC3 showed 13.3\% PC4 exhibited 10.5\% and PC5 exhibited 10.23\% variability among the RIL population for the traits under study. Principal component one (PC1), principal component two (PC2), principal component three (PC3), principal component four (PC4) and principal component five (PC5) had Eigen values of 1.79, 1.46, $1.33,1.04$ and 1.023 , respectively.
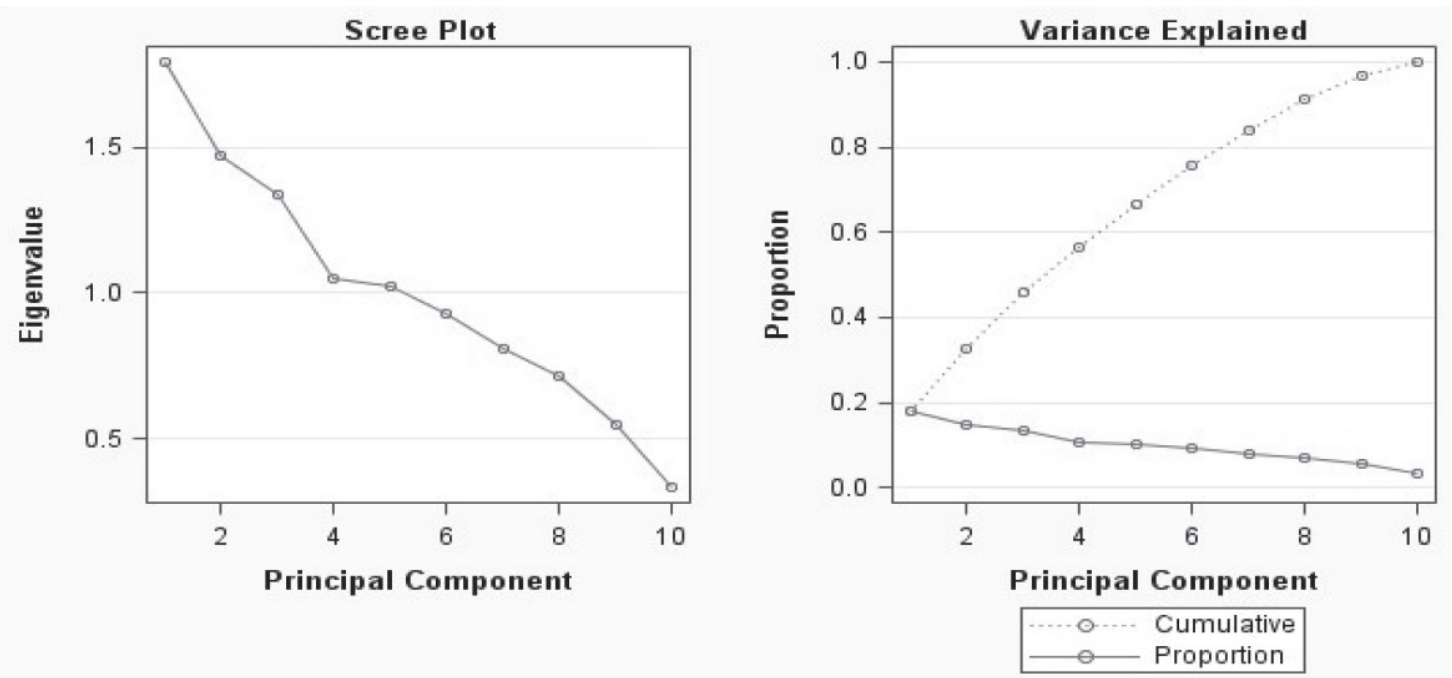

Figure 1. PCA Scree plot and Cumulative variance of RIL population

Table 4. Eigen values, contribution of variability and factor loading for the principal component axis in 100 Swarna x Type 3 RIL population of rice

\begin{tabular}{lccccc}
\hline & PC $\mathbf{1}$ & PC 2 & PC 3 & PC 4 & PC 5 \\
\hline Eigenvalue & 1.79 & 1.46 & 1.33 & 1.04 & 1.023 \\
Variability (\%) & 17.9 & 14.6 & 13.3 & 10.5 & 10.23 \\
Cumulative (\%) & 17 & 32.5 & 45.9 & 56.4 & 66.6 \\
Days to fifty percent flowering & -0.10 & -0.34 & 0.32 & 0.10 & -0.35 \\
Plant height & 0.11 & 0.54 & -0.25 & 0.10 & -0.16 \\
Panicle length & -0.04 & 0.25 & -0.38 & 0.55 & -0.23 \\
Number of tillers & 0.002 & 0.10 & -0.20 & -0.45 & 0.55 \\
Panicle weight & -0.09 & 0.27 & 0.41 & -0.32 & -0.44 \\
Filled grains per panicle & -0.10 & -0.27 & 0.26 & 0.53 & 0.37 \\
Single plant yield & -0.37 & 0.38 & 0.19 & 0.20 & 0.32 \\
Test weight & -0.22 & 0.41 & 0.48 & 0.042 & 0.12 \\
Grain Iron & 0.62 & 0.18 & 0.16 & 0.11 & 0.028 \\
Grain zinc & 0.60 & 0.05 & 0.31 & 0.10 & 0.16 \\
\hline
\end{tabular}


According to PC 1 grain iron (0.62) and grain zinc (0.60) had relatively higher contributions to the total morphological variability, whereas it is negatively correlated with panicle weight, single plant yield, test weight, number of filled grains and panicle length. The highly positive correlated variables with PC2 were plant height (0.54), test weight $(0.41)$ and single plant yield (0.38), whereas number of filled grains per panicle and days to fifty percent flowering are negatively correlated. The other component PC3 was positively correlated with test weight (0.48) and panicle weight (0.41) and negatively correlated with plant height, panicle length and number of tillers per plant. The component PC4 was positively correlated with panicle length (0.55) and number of unfilled grains per panicle (0.53) and negatively correlated with number of tillers per plant. The variables which are positive and strongly correlated with PC5 were number of tillers (0.55), filled grains per panicle (0.37) and single plant yield (0.32) contributing $10.5 \%$ variability and negatively correlated with days to fifty percent flowering, plant height and panicle weight.

On the basis of PCA analysis from Figure 2, the first two principal components (PC1 and PC2)accounted for 45\%

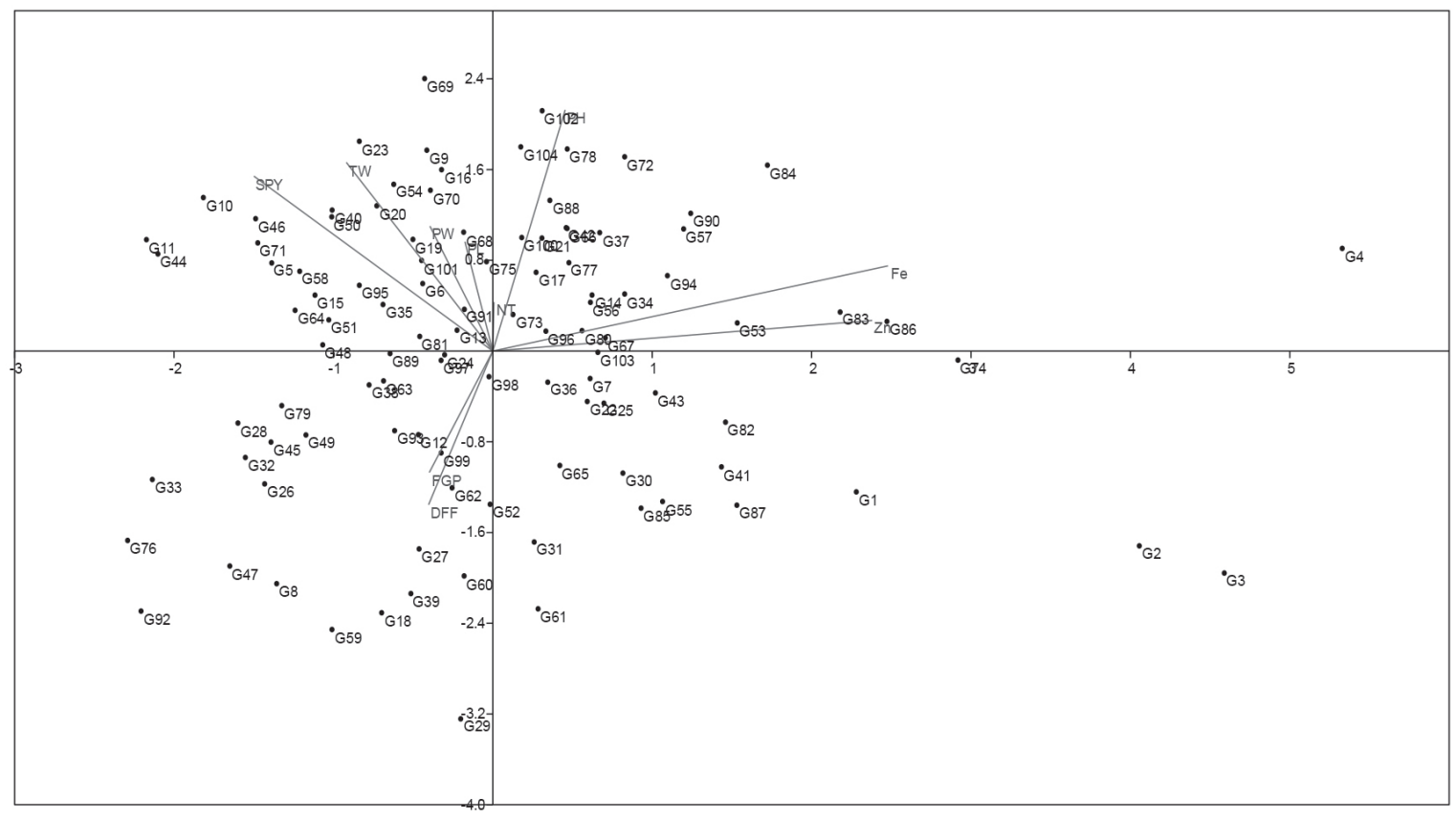

Component 1

Figure 2. Principal component $1 \& 2$ of RIL population

of the genetic variance. Similar results were reported by Worede et al. (2014) for 32.5\% of the total variability using the first and second PCs. Selection of traits via grain iron, grain zinc, plant height and test weight lying in these two principal components would be beneficial in contributing to the total morphological diversity.

\section{Conclusion}

In the present study critical analysis of character association and path analysis indicated that the test weight possessed both positive association and high positive direct effects. Hence, selection for these trait could bring improvement in yield and yield components.
PCA identified grain iron, grain zinc, plant height and test weight in different principal components playing a prominent role in classifying the variation existing in the population. Two RILs viz, P45 \& P57 have shown higher grain yield per plant with high zinc and iron concentration presented in the Table 5. These RILs need to be evaluated in multilocation to access further of their yield and nutritional value in different environments. Stable high yielding lines in combination with high $\mathrm{Zn}$ and Fe can be a good source of genetic variability for the improvement of rice. These lines also serve as potential donor in further rice biofortification programme especially for enhanced grain zinc and iron content. 
Table 5. List of RILs with high grain yield, grain iron and zinc concentration

\begin{tabular}{lcccc}
\hline S. No. & Genotype & Single plant yield $(\mathbf{g})$ & $\begin{array}{c}\text { Zinc concentration } \\
(\mathbf{p p m})\end{array}$ & $\begin{array}{c}\text { Iron concentration } \\
(\mathbf{p p m})\end{array}$ \\
\hline 1 & $\mathrm{P} 45$ & 21 & 28.5 & 16.1 \\
2 & $\mathrm{P} 57$ & 21.7 & 27.10 & 16 \\
\hline
\end{tabular}

\section{Compliance with ethical standards}

NA

\section{Conflict of Interest}

Authors declare that they have no conflict of interest

\section{Authors' contribution}

Conceptualization of research (SD, NCN, CC, GSV); Designing of the experiments ( $\mathrm{SD}, \mathrm{NCN}, \mathrm{CC})$; Contribution of experimental material (NCN); Execution of field experiments and data collection (SD, NCN); Analysis of data and interpretation (SD, NCN, GSV); Preparation of the manuscript (SD, NCN, CC, GSV).

\section{Declaration}

The authors declare no conflict of interest.

\section{Acknowledgement}

Authors are thankful to PJTSAU and ICAR-Indian Institute of Rice Research, Rajendranagar, Hyderabad for providing facilities and financial support.

\section{References}

1. Ali A, AS Khan and MA Asad. 2002. Drought tolerance in wheat: genetic variation and heritability for growth and ion relations. Asian Journal of Plant Science 1: 420-422.

2. Devi RK, K Parimala, V Venkanna, N Lingaiah, Y Hari and SB Chandra. 2016. Estimation of variability for grain yield and quality traits in rice (Oryza sativa L.). International Journal of Pure E Applied Bioscience 4: 250-255.

3. Gangashetty P, P Salimath and N Hanamaratti. 2013. Genetic variability studies in genetically diverse nonbasmati local aromatic genotypes in rice (Oryza sativa L.). Rice Genomics and Genetics 4: 4-8.

4. Hanson CH, HF Robinson and RK Comstock. 1956. Biometrical studies on yield in segregating population of Korean Lasphadezia. Agronomy Journal 48: 314-318.
5. Johnson HW, HF Robinson and RE Comstock. 1955. Estimates of genetic and environmental variability in soybeans. Agronomy Journal 47:314-318.

6. Kalyan B, KV Radha Krishna and LVS Rao. 2017. Path coefficient analysis for yield and yield contributing traits in rice (Oryza sativa L.) genotypes. International Journal of Current Microbiology and Applied Sciences 6: 2680-2687.

7. Karande SS, BL Thaware, SG Bhave and MM Burondkar. 2015. Estimate of genetic variability and heritability in some exotic germplasm lines in Kharif rice (Oryza sativa L.). International Journal of Applied Biology and Pharmaceutical Technology 6: 128-130.

8. Lakshmi L, BMN Rao, S Raju and NS Reddy. 2017. Variability, correlation and path analysis in advanced generation of aromatic rice. International Journal of Current Microbiology and Applied Sciences 6: 1798-1806.

9. Nandeshwar BC, S Pal, BK Senapati and DK De. 2015. Genetic variability and character association among biometrical traits in $\mathrm{F}_{2}$ generation of some rice crosses. Electronic Journal of Plant Breeding 1: 758-763.

10. Nagesh, VR Babu, GU Rani, TD Reddy, K Surekha and DVV Reddy. 2013. Association of grain iron and zinc contents with yield in high yielding rice cultivars. Oryza 50: 41-44.

11. Noirot M, S Hamon and F Anthony. 1996. The principal component scoring: a new method of constituting a core collection using quantitative data. Genetics Resource Crop Evolution 43: 1-6.

12. Padmaja D, K Radhika, LVS Rao and V Padma. 2011. Correlation and path analysis in rice germplasm. Oryza 48: 69-72.

13. Paltridge NG, LJ Palmer, PJ Milham, GE Guild and JCR Stangoulis. 2012. Energy dispersive X-ray fluorescence analysis of zinc and iron concentration in rice and pearl millet grain. Plant Soil 11: 21-32. 
14. Priya S, Y Suneetha, RD Babu and SV Rao. 2017. Inter-relationship and path analysis for yield and quality characters in rice (Oryza sativa L.). International Journal of Science and Environment Technology 6: 381-390.

15. Rahman MA, MS Hossain, IF Chowdhury, MA Matin and H Mehraj. 2014. Variability study of advanced fine rice with correlation, path co-efficient analysis of yield and yield contributing characters. International Journal of Applied Science and Biotechnology 2: 364-370.

16. Rao VT, YC Mohan, D Bhadru, D Bharathi and V Venkanna. 2014. Genetic variability and association analysis in rice. International Journal of Applied Biology and Pharmaceutical Technology. 5(2): 385-391.

17. Ritchie H, DS Reay and P Higgins. 2018. Quantifying, Projecting and Addressing India's Hidden Hunger Front. Sustain. Food Syst., https://doi.org/10.3389/ fsufs.2018.00011.

18. Sameera SK, AP Rajesh, V Jayalakshmi, PJ Nirmala and T Srinivas. 2015. Genetic variability studies for yield and yield components in rice (Oryza sativa L.). Electronic Journal of Plant Breeding 6: 269-273.

19. Sathish V and BK Senapati. 2017. Study of genetic diversity in some newly developed Rice genotypes. International Journal of Current Microbiology and Applied Sciences 6: 2693-2698.
20. Seyoum M, S Alamerew and K Bantte. 2012. Genetic variability, heritability, correlation coefficient and path analysis for yield and yield related traits in upland rice (Oryza sativa L.). Journal of Plant Science 7: 13-22.

21. Tenorio FA, C Ye, E Redona, S Sierra and M Laza. 2013. Screening rice genetic resources for heat tolerance. SABRAO Journal of Breeding and Genetics 45: 371-381.

22. Wani SH, JR Choudhary, M Choudhary, M Rana and SS Gosal. 2020. Recent advances in genomics assisted breeding for drought stress tolerance in major cereals. Journal of Cereal Research 12(1): 1-12.

23. Worede F, T Sreewongchai, C Phumichai and P Sripichitt. 2014. Multivariate analysis of genetic diversity among some rice genotypes using morphoagronomic traits. Journal of Plant Science 9: 14-24.

24. Wright S. 1923. The theory of path coefficients a reply to Niles's criticism. Genetics 8: 239.

25. Zafar I, M Arshad, M Ashraf, T Mahmood and W Abdul. 2008. Evaluation of soybean (Glycine max L.) Merrill germplasm for some important morphological traits using multivariate analysis. Pakistan Journal of Botany 40: 2323-2328. 